\title{
Methotrexate-induced cutaneous ulceration in patients with erythrodermic mycosis fungoides
}

\author{
Debra L Breneman' \\ Timothy J Storer ${ }^{2}$ \\ John C Breneman ${ }^{3}$ \\ Diya F Mutasim ${ }^{4}$ \\ 'University of Cincinnati Medical \\ Center, Dept of Dermatology, \\ Cincinnati, Ohio, USA; ${ }^{2}$ Smith Clinic, \\ Delaware, Ohio, USA; ${ }^{3}$ University \\ of Cincinnati Medical Center, Dept \\ of Radiology, Division of Radiation \\ Oncology, Cincinnati, Ohio, USA; \\ ${ }^{4}$ University of Cincinnati Medical \\ Center, Dept of Dermatology, \\ Cincinnati, Ohio, USA
}

\begin{abstract}
Methotrexate-induced cutaneous ulceration has rarely been reported in patients with mycosis fungoides. We report 4 patients with mycosis fungoides who developed cutaneous ulceration as an initial manifestation of methotrexate toxicity. Methotrexate dose at the time of ulceration ranged from 10-60 mg. All 4 patients were erythrodermic, which may have predisposed them to this toxic effect. It is important to recognize cutaneous ulceration as an uncommon, but potentially serious, side effect of methotrexate in these patients, and to differentiate it from ulceration due to progressive lymphoma.
\end{abstract}

Keywords: mycosis fungoides, methotrexate, ulceration, cutaneous T-cell lymphoma, toxicity

\section{Introduction}

The use of methotrexate as a therapeutic agent in the treatment of cutaneous T-cell lymphoma (CTCL) is well established (McDonald and Bertino 1978; Zackheim and Epstein 1989; Zackheim et al 1996, 2003). There have been rare reports of cutaneous erosion and/or ulceration occurring in patients with mycosis fungoides treated with methotrexate (McDonald and Bertino 1978; Zackheim and Epstein 1989; Zackheim et al 1996). However, methotrexate-induced cutaneous ulceration may be misdiagnosed when treating patients with mycosis fungoides, as it can be easily mistaken for ulceration associated with disease progression.

We report 4 patients with erythrodermic mycosis fungoides who developed cutaneous ulceration as a manifestation of methotrexate toxicity. In all patients the etiologic differential diagnosis included tumor ulceration due to progressive lymphoma.

\section{Case reports}

\section{Patient I}

An 81-year-old previously healthy African-American male with a long history of patch stage mycosis fungoides, presented with multiple large cutaneous tumors involving most prominently the axillae and anterior thighs. Also present were numerous hyperpigmented patches and plaques, covering approximately $35 \%$ of the skin surface. The tumors resolved with local radiotherapy, but his skin disease progressed to erythroderma.

The patient was placed on methotrexate $10 \mathrm{mg}$ per week by mouth. Other medications were lorazepam and hydroxyzine. After 7 weeks of methotrexate therapy, the patient developed multiple angulated, clean-based erythematous ulcers involving the axillae, groin, buttocks, right thigh, and right posterior leg (Figure 1). Creatinine was $1.4 \mathrm{mg} / \mathrm{dL}$, blood urea nitrogen $18 \mathrm{mg} / \mathrm{dL}$, hemoglobin $11.6 \mathrm{~g} / \mathrm{dL}$, white blood cell count $9,400 \mathrm{~mm}^{3}$, and platelet count $160,000 \mathrm{~mm}^{3}$. Biopsies of the ulcers revealed full-thickness epidermal loss with underlying necrosis of the papillary dermis, felt to 


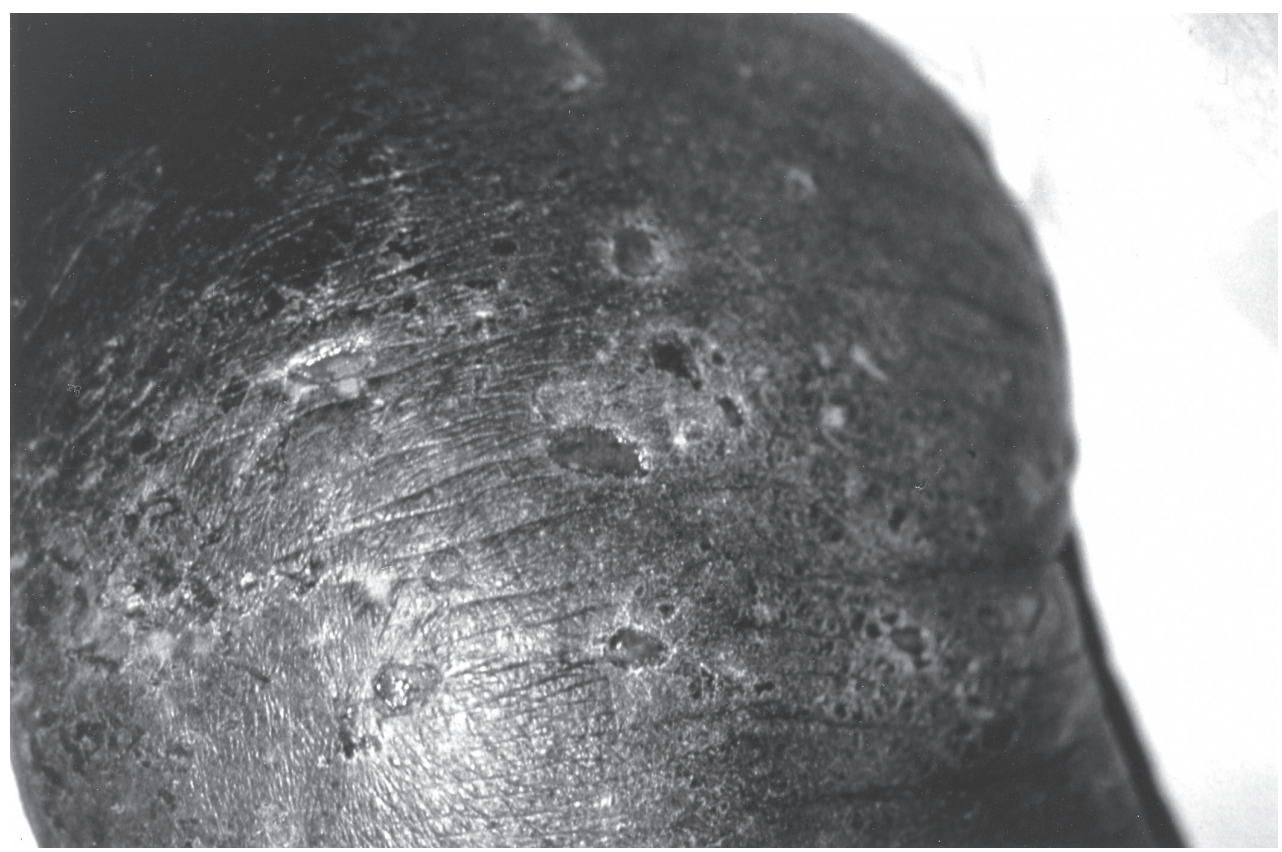

Figure I Multiple punched-out ulcers on the leg of an 81 year old African-American male on methotrexate for 7 weeks.

be highly consistent with methotrexate-induced cutaneous toxicity. Additionally, there was a moderately dense perivascular and diffuse mixed infiltrate of mononuclear cells and eosinophils in the superficial and deep dermis, with many of the mononuclear cells having hyperchromatic nuclei. Similar cells with hyperchromatic nuclei were seen within the epidermis both singly and in groups. A viral culture obtained from a cutaneous ulcer was negative.

The methotrexate was discontinued and the ulcerations healed without further sequelae. The patient was subsequently treated with total skin irradiation with marked improvement of his erythroderma.

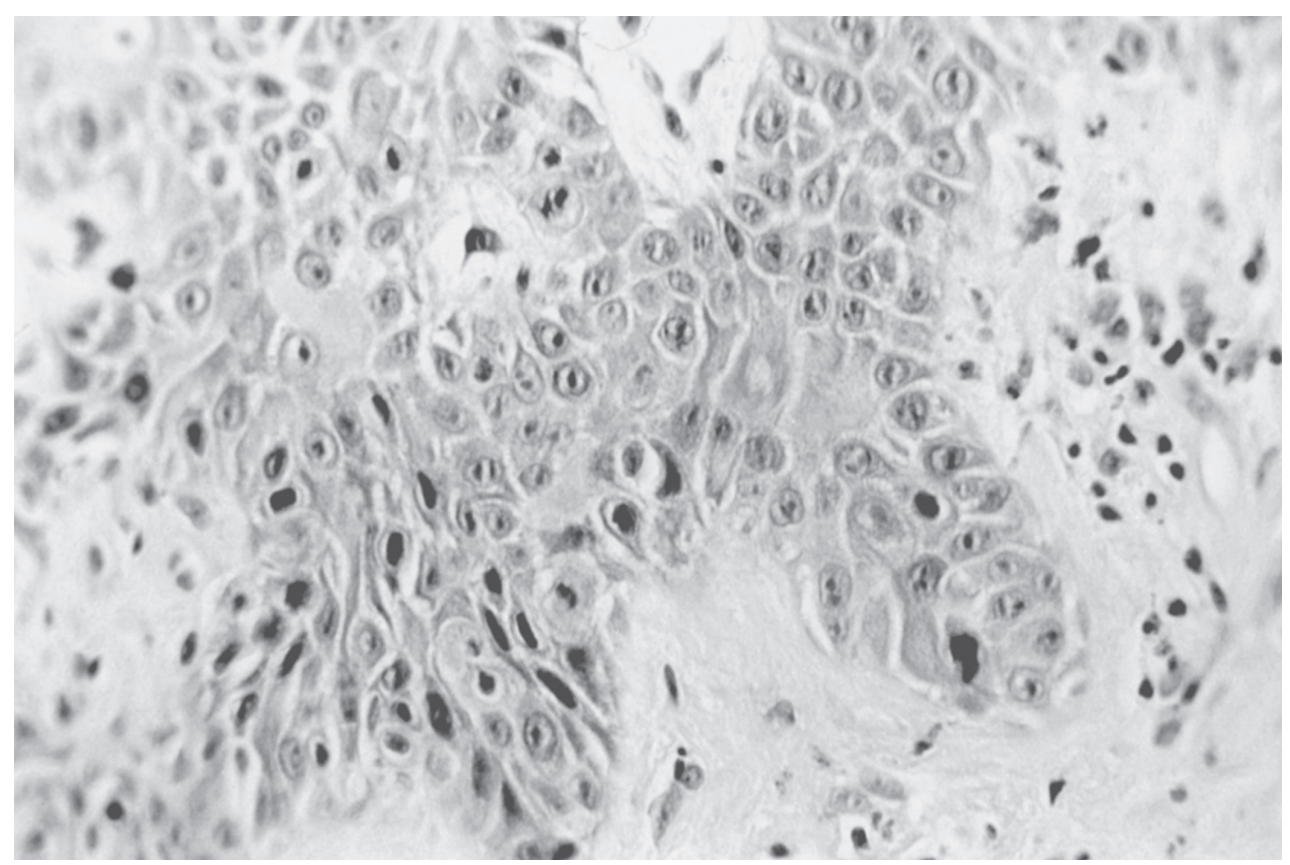

Figure 2 Biopsy of skin adjacent to ulcer revealing disorganization of epidermal cells, moderate pleomorphism and dyskeratosis; magnification $\times 400$. 


\section{Patient 2}

A 78-year-old Caucasian male with a two year history of patch stage mycosis fungoides, was seen with new development of multiple cutaneous nodules, erythroderma, and severe pruritus.

The patient was begun on $40 \mathrm{mg}$ per week of methotrexate intravenously. Other medications were potassium chloride, flutamide and furosemide. Three weeks later he developed multiple 1- to 6-cm sharply marginated, oval, bleeding, shallow ulcers over the buttocks, posterior thighs, arms, upper back, and scalp. Blood urea nitrogen was $102 \mathrm{mg} / \mathrm{dL}$, creatinine $2.4 \mathrm{mg} / \mathrm{dL}$, hemoglobin $8.6 \mathrm{mg} / \mathrm{dL}$, hematocrit $25.5 \%$, WBC $3,000 / \mathrm{mm}^{3}$, and platelet count $92,000 / \mathrm{mm}^{3}$. Viral culture from an ulcer was negative.

Skin biopsy from skin adjacent to an ulcer revealed disorganization of epidermal cells, moderate pleomorphism, and dyskeratosis. A mild polymorphous infiltrate of mononuclear cells with a few multinucleated giant cells was present in the upper dermis (Figure 2). These findings were considered to be consistent with cutaneous methotrexate toxicity.

Methotrexate was discontinued and the patient was treated with oral VP16. The cutaneous ulcers re-epithelialized, but the patient expired two months later secondary to progressive mycosis fungoides.

\section{Patient 3}

A 77-year-old African-American female, with a 3-year history of patch stage mycosis fungoides, was seen because of disease progression to erythroderma. Examination revealed diffuse exfoliative erythroderma. Laboratory test results included: blood urea nitrogen $24 \mathrm{mg} / \mathrm{dL}$, serum creatinine $1.3 \mathrm{mg} / \mathrm{dL}$, hemoglobin $11.5 \mathrm{~g} / \mathrm{dL}$, hematocrit $34.4 \%$, white blood cell count $6,100 / \mathrm{mm}^{3}$, and platelet count $276,000 / \mathrm{mm}^{3}$.

Methotrexate was started at a dose of $10 \mathrm{mg}$ per week by mouth, and gradually escalated over 8 weeks to a dose of 40 mg per week by mouth. Other medications were etretinate, mechlorethamine hydrochloride, and hydroxyzine. Twelve weeks after initiation of methotrexate, the patient developed multiple cutaneous erosions and ulcerations over her scalp, face, and trunk, with a $20 \mathrm{~cm}$ ulceration over her buttocks (Figure 3). Laboratory studies included: blood urea nitrogen $13 \mathrm{mg} / \mathrm{dL}$, serum creatinine $0.9 \mathrm{mg} / \mathrm{dL}$, hemoglobin $10.4 \mathrm{~g} / \mathrm{dL}$, hematocrit $30.1 \%$, white blood cell count $3,400 / \mathrm{mm}^{3}$, and platelet count $325,000 / \mathrm{mm}^{3}$. A skin biopsy obtained from tissue adjacent to an erosion revealed a few lymphocytes migrating into the epidermis. There was papillary dermal edema with a surrounding mild lymphocytic infiltrate, melanophages and occasional eosinophils. Methotrexate was stopped, and no new ulcerations developed. Within three weeks, all of the ulcerations

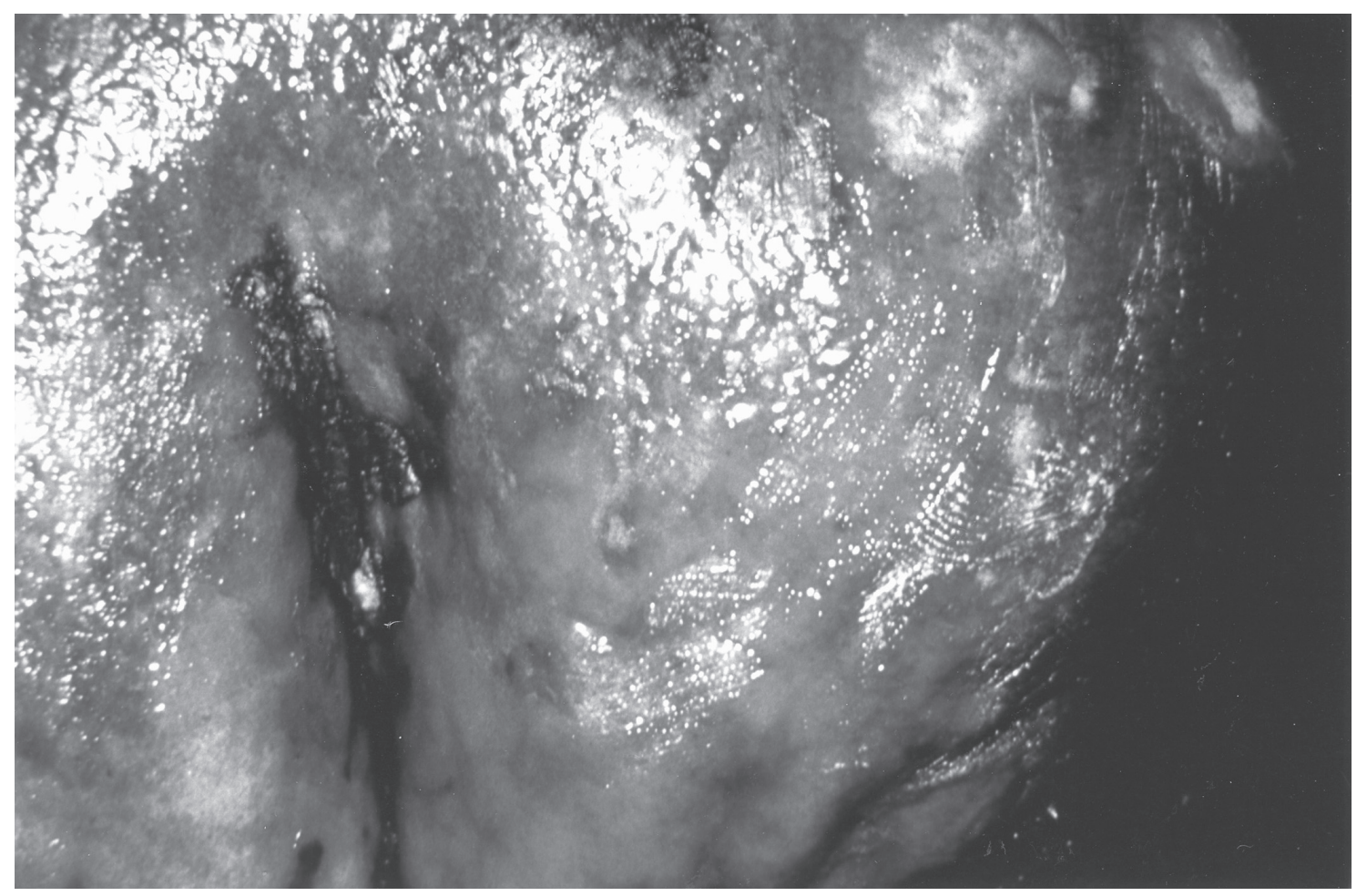

Figure 3 Large cutaneous ulcer over the buttocks in a 77 year old African-American female on methotrexate for 12 weeks. 
had re-epithelialized. The patient was subsequently placed on a combination of deoxycoformycin intravenously and alphainterferon subcutaneously with an excellent clinical response.

\section{Patient 4}

A 67-year-old African-American male with a 4-year history of patch/plaque stage mycosis fungoides was seen because of progression to erythroderma. Cutaneous examination revealed a diffuse exfoliative erythroderma. Methotrexate was initiated at a dose of $50 \mathrm{mg}$ per week intravenously, and six months later, this dose was increased to $60 \mathrm{mg}$ per week intravenously. There were no concurrent medications. His erythroderma improved dramatically, and he was maintained on $60 \mathrm{mg}$ methotrexate per week. Four and a half years later, he presented with multiple cutaneous erosions in the axillae, groin, and gluteal cleft (Figure 4). Serum methotrexate level was 3 times the upper therapeutic limit. His laboratory studies included: blood urea nitrogen $92 \mathrm{mg} / \mathrm{dL}$, serum creatinine $11.5 \mathrm{mg} / \mathrm{dL}$, hemoglobin $13.9 \mathrm{~g} / \mathrm{dL}$, hematocrit $42 \%$, white blood cell count $1,100 / \mathrm{mm}^{3}$, and platelet count $182,000 / \mathrm{mm}^{3}$.

It was determined that the patient had post-obstructive acute renal failure, with methotrexate toxicity secondary to decreased excretion of the drug. His methotrexate was discontinued, and he was treated with folate, leucovorin, intravenous fluids and placement of a urinary catheter.

Histologic examination of a biopsy specimen, from skin adjacent to an erosion, showed vacuolar degeneration of the basal cells and a sparse lymphocytic infiltrate containing several melanophages (Figure 5). Histologic examination of a biopsy specimen from the margin of an erosion showed almost complete epidermal necrosis and a mild lymphocytic infiltrate with melanophages (Figure 6).

As serum methotrexate levels normalized, the ulcers began to re-epithelialize, and no new ulcerations developed. His blood urea nitrogen and serum creatinine levels normalized to $21 \mathrm{mg} / \mathrm{dL}$ and $1.3 \mathrm{mg} / \mathrm{dL}$ respectively. One month later, the ulcers were noted to be completely healed. The patient was subsequently restarted on methotrexate $30 \mathrm{mg}$ per week intravenously, following a transurethral resection of the prostate, and no further ulcers developed.

\section{Discussion}

The occurrence of cutaneous ulceration as a side effect of methotrexate therapy in the treatment of psoriasis, has been occasionally reported (Baker 1970; Lawrence and Dahl 1982,

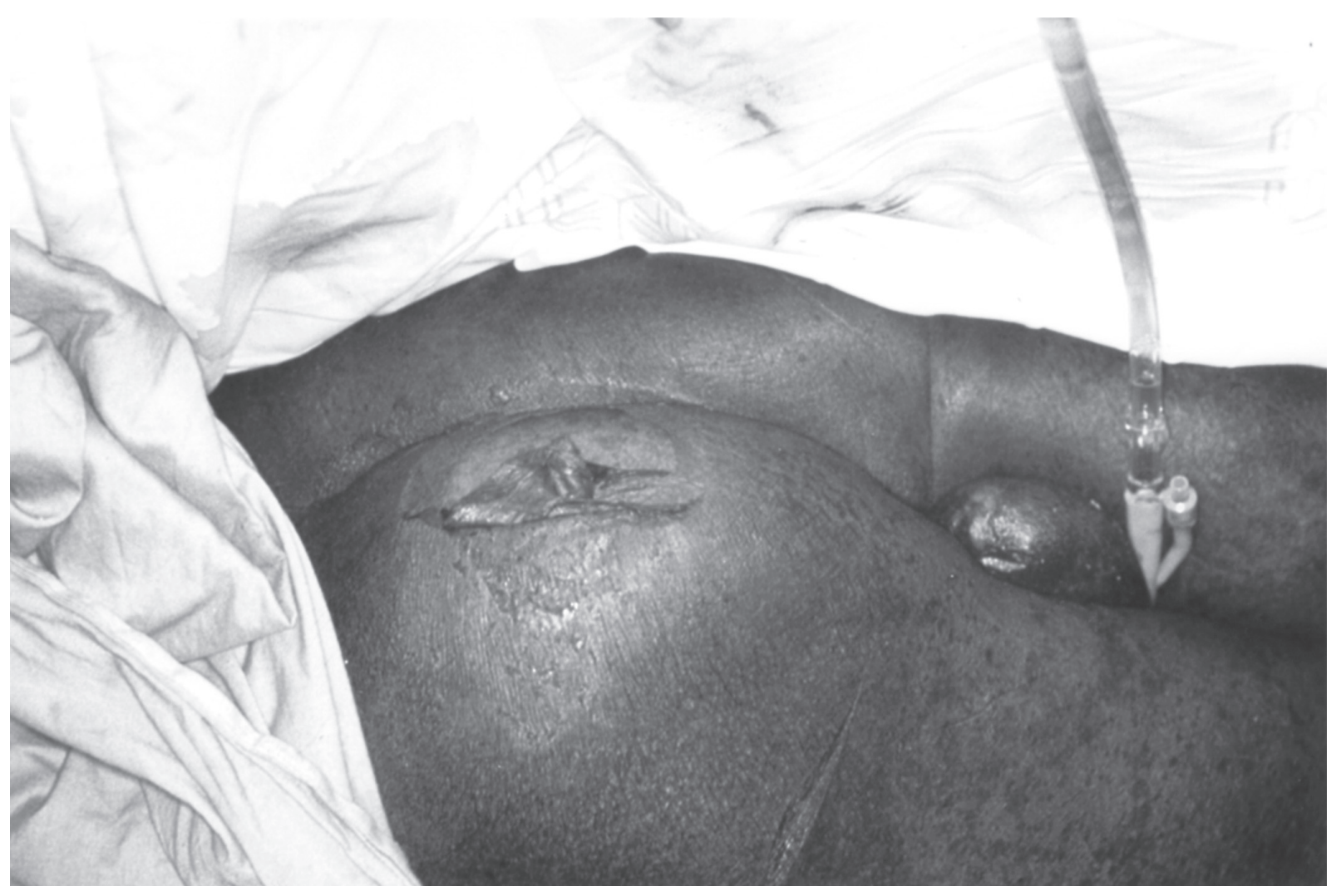

Figure 4 Angulated ulcers occurring in a 72 year old African-American male after 5 years of methotrexate therapy. 


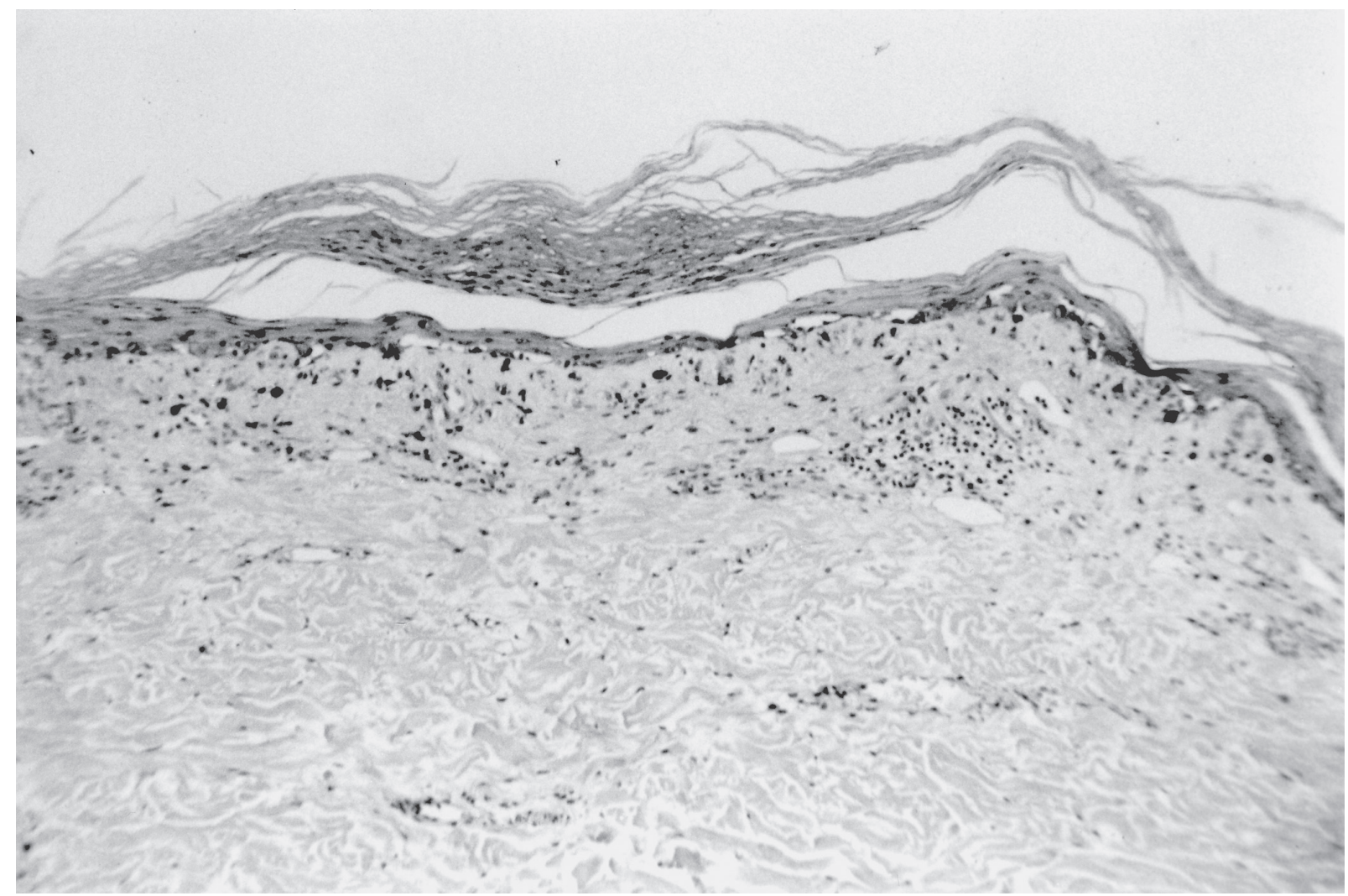

Figure 5 Biopsy obtained adjacent to an erosion showing marked epidermal atrophy, vacuolar degeneration of the basal cells, and a sparse lymphocytic infiltrate; magnification $\times 100$.

1984; Reed and Sober 1983; Kaplan and Olsen 1988; Pearce and Braunstein 1996; Primka and Camisa 1997; Kazlow et al 2003). In addition to the rare occurrence of a toxic epidermal necrolysis-like condition, two different patterns of ulcerations have been described in these patients; one type in psoriatic plaques and the other type in skin uninvolved by psoriasis but affected by other cutaneous pathology, such as stasis dermatitis or scars (Lawrence and Dahl 1984; Primka and Camisa 1997). In patients with cutaneous T-cell lymphoma, cutaneous ulcerations have only rarely been reported as a side effect of methotrexate therapy (McDonald and Bertino 1978; Zackheim and Epstein 1989; Zackheim et al 1996).

Cutaneous ulcerations have been described as a possible first sign of methotrexate toxicity in psoriasis patients (Baker 1970; Lawrence and Dahl 1982, 1984; Kaplan and Olsen 1988; Pearce and Braunstein 1996). Likewise, the cases we present demonstrate that cutaneous ulceration may be the first sign of methotrexate toxicity in patients with erythrodermic mycosis fungoides. In 3 of our patients, cutaneous ulceration developed after relatively short methotrexate treatment periods ( 3 weeks, 7 weeks, and 12 weeks). In the fourth patient, ulceration occurred after 5 years of methotrexate therapy, but in this patient methotrexate toxicity was clearly related to post-obstructive acute renal failure. There was a wide range of methotrexate dosages used at the time of ulceration, with $10 \mathrm{mg}$ being the lowest dose and $60 \mathrm{mg}$ being the highest dose administered.

The most common risk factors in psoriatics who developed methotrexate-induced cutaneous ulceration, were alteration in methotrexate dosage, and concomitant use of nonsteroidal anti-inflammatory drugs (Pearce and Braunstein 1996). A number of drugs may influence the metabolism of methotrexate, or potentiate methotrexate-induced toxicity. These include salicylic acid and non-steroidal anti-inflammatory drugs (Naldi and Griffiths 2005). None of our patients were taking any of these medications, however. Patient 2 was taking furosemide concomitantly with the methotrexate, and it has been suggested that furosemide may produce toxic methotrexate levels by increasing methotrexate tubular secretion. However, experimental data in support of such an interaction is lacking (Lawrence and Dahl 1984). Impaired renal function may impair methotrexate elimination, causing methotrexate toxicity from increased serum levels of the drug (Pearce and Braunstein 1996). This likely contributed to toxicity in Patient 4 and possibly Patient 2. Because impaired renal function can predispose patients to toxic effects of 


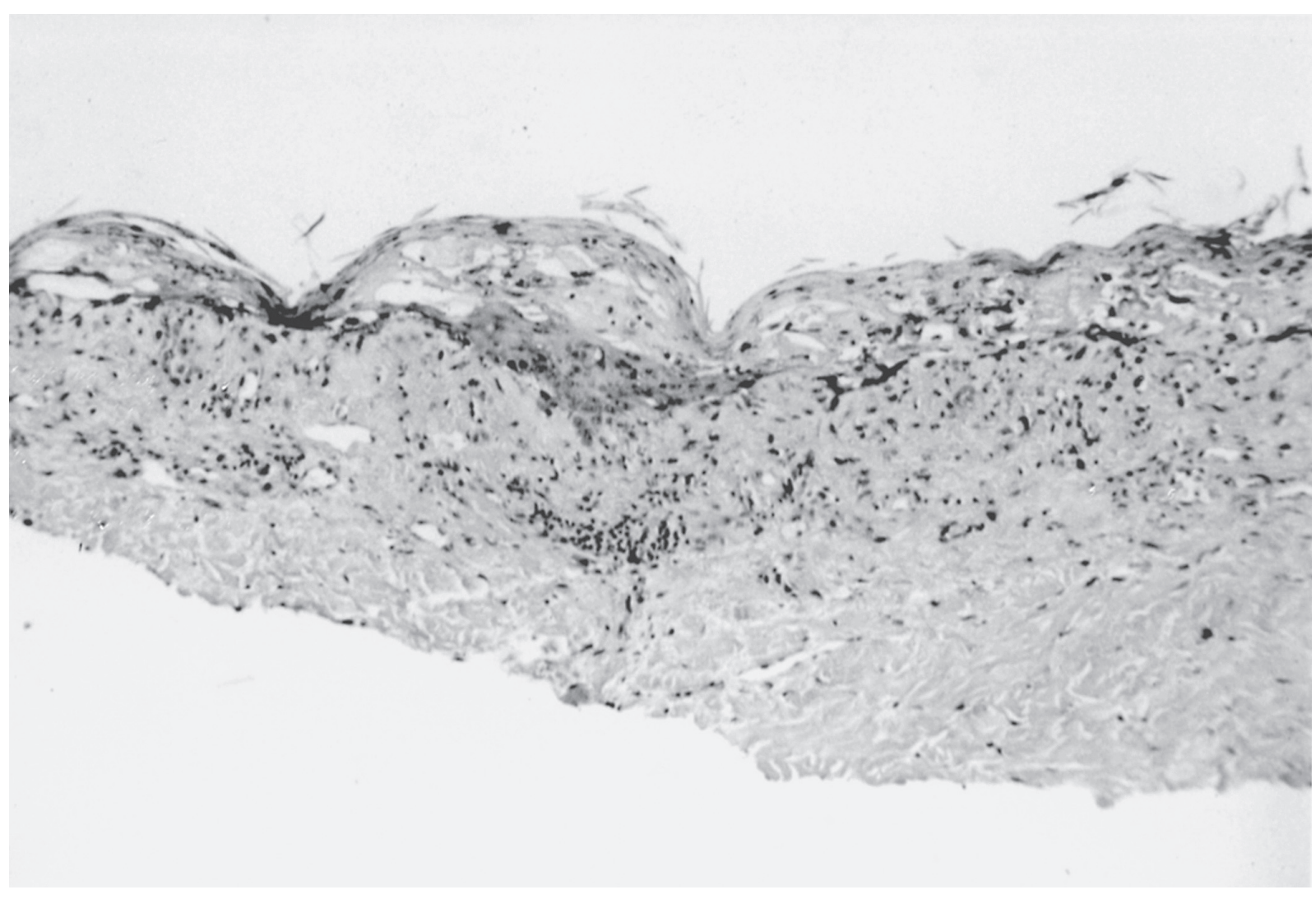

Figure 6 Biopsy of skin from the margin of an erosion showing almost complete epidermal necrosis and mild lymphocytic infiltrate with melanophages; magnification $\times 100$.

methotrexate, including cutaneous ulceration, it is important to monitor renal status throughout treatment.

Methotrexate-induced cutaneous ulceration is rare in patients with no underlying skin disease (Aractingi et al 1992; Ben-Amitai et al 1998). One reported patient developed extensive cutaneous erosion after being given methotrexate intravenously to treat high-grade lymphoma (Aractingi et al 1992) and another patient developed recurrent skin ulcers concurrent with methotrexate administration for seronegative arthralgias (Ben-Amitai et al 1998). Of particular note, all four of our patients were erythrodermic when they developed methotrexate-induced cutaneous ulceration, and the ulceration occurred primarily on erythrodermic skin, rather than at the sites of nodules/tumors. It appears that most of the CTCL patients previously reported to have developed methotrexate toxicity were also erythrodermic (Zackheim and Epstein 1989; Zackheim et al 1996). Many patients with erythroderma also have exfoliation. The epidermis of patients with exfoliative erythroderma has a shorter cellular turnover time and a higher rate of metabolic activity, and because methotrexate is an S-phase specific therapy, it is most active against rapidly dividing cells (Olsen 1991). This suggests that patients with erythrodermic mycosis fungoides may form a subset of mycosis fungoides patients more susceptible to methotrexate-induced cutaneous ulceration.

The mechanism of cutaneous necrosis and ulceration due to methotrexate therapy may be due to the antiproliferative effects of the drug. Methotrexate-induced skin necrolysis has been reported to be dose dependent, suggesting a toxic drug effect with the toxic dosage being dependent on the individual (Yang et al 2000). In patients with toxic serum levels, or possibly with an increased sensitivity to methotrexate, there may be significant necrosis of dividing cells in a particular area of skin, to the point that there are no dividing cells in the basal layer to replace the layers undergoing sloughing. Because of the rapid turnover of epithelium in areas of erythroderma, erythrodermic patients may be particularly sensitive to this toxic effect.

The clinical and histological findings in our four patients demonstrate that methotrexate therapy can induce cutaneous ulceration in patients with erythrodermic mycosis fungoides. It is important for clinicians to recognize this as an uncommon but potentially serious side effect in patients with cutaneous T-cell lymphoma. The development of multiple cutaneous erosions or ulcerations, in a patient with advanced cutaneous mycosis fungoides, could easily be misconstrued 
to represent progressive lymphoma. If the methotrexate is continued, or the dosage is increased in this situation, it could lead to the development of more extensive ulceration, with the potential for sepsis and even death. Thus, patients with mycosis fungoides being treated with methotrexate, should be advised that should ulcers develop, the drug should be stopped and their physicians notified immediately. Appropriate treatment is dependent upon the correct diagnosis, and therefore, recognizing methotrexate as a possible cause of cutaneous ulceration in these patients is essential for appropriate patient management.

\section{Acknowledgment}

The authors would like to thank Mrs. Janet Burdsall for her excellent secretarial assistance in preparing this manuscript.

\section{Disclosures}

This manuscript was not funded, and the authors have no conflicts of interest to disclose.

\section{References}

Aractingi S, Briant E, Marolleau JP, et al. 1992. Décollements cutane's induits par le méthotrexate. Presse Méd, 21:1668-70.

Baker H. 1970. Intermittent high-dose oral methotrexate therapy in psoriasis. Br J Dermatol, 82:65-9.

Ben-Amitai D, Hodak E, David M. 1998. Cutaneous ulceration: An unusual sign of methotrexate toxicity - first report in a patient without psoriasis. Ann Pharmacother, 32:651-3.
Kaplan DL, Olsen EA. 1988. Erosion of psoriatic plaques after chronic methotrexate administration. Int J Dermatol, 27:50-62.

Kazlow DW, Federgrun D, Kurtin S, et al. 2003. Cutaneous ulceration caused by methotrexate. J Am Acad Dermatol, 49:S197-8.

Lawrence C, Dahl M. 1982. Cutaneous necrosis associated with methotrexate treatment of psoriasis. Br J Dermatol, 107(Suppl 22):24.

Lawrence C, Dahl M. 1984. Two patterns of skin ulceration induced by methotrexate in patients with psoriasis. $J$ Am Acad Dermatol, 11:1059-65.

McDonald CJ, Bertino JR. 1978. Treatment of mycosis fungoides: Effectiveness of infusions of methotrexate followed by oral citrovorum factor. Cancer Treat Rep, 62:1009-14.

Naldi L, Griffiths CEM. 2005. Traditional therapies in the management of moderate to severe chronic plaque psoriasis: An assessment of the benefits and risks. Br J Dermatol, 152:597-615.

Olsen EA. 1991. The pharmacology of methotrexate. J Am Acad Dermatol, $25: 306-18$.

Pearce HP, Braunstein B. 1996. Erosion of psoriatic plaques: An early sign of methotrexate toxicity. J Am Acad Dermatology, 35:835-8.

Primka EJ, Camisa C. 1997. Methotrexate-induced toxic epidermal necrolysis in a patient with psoriasis. $J$ Am Acad Dermatol, 36:815-8.

Reed KM, Sober AJ. 1983. Methotrexate-induced necrolysis. J Am Acad Dermatol, 8:677-9.

Yang C, Yang LJ, Jaing TH, et al. 2000. Toxic epidermal necrolysis following combination of methotrexate and trimethoprim-sulfamethoxazole. Int J Dermatol, 39:621-4.

Zackheim HS, Epstein EH Jr. 1989. Low-dose methotrexate for the Sézary syndrome. J Am Acad Dermatol, 21:757-62.

Zackheim HS, Kashani-Sabet M, Hwang ST. 1996. Low-dose methotrexate to treat erythrodermic cutaneous T-cell lymphoma: Results in twentynine patients. J Am Acad Dermatol, 34:626-31.

Zackheim HS, Kashani-Sabet M, McMillan A. 2003. Low-dose methotrexate to treat mycosis fungoides: A retrospective study in 69 patients. $J$ Am Acad Dermatol , 49:873-8. 
